\title{
Mercury speciation in sediments of a historic industrially used canal in Northern Germany using SSID GC- ICP-ToF-MS
}

\author{
SEBASTIAN FASSBENDER ${ }^{1}$, MARCUS VON DER AU ${ }^{1}$, \\ CHRISTIAN PIECHOTTA ${ }^{2}$, JOCHEN VOGL ${ }^{1}$ AND BJÖRN \\ MEERMANN $^{1}$ \\ ${ }^{1}$ Federal Institute for Materials Research and Testing (BAM) \\ ${ }^{2}$ Bundesanstalt für Materialforschung und -prüfung \\ Presenting Author: sebastian.fassbender@bam.de
}

Sediments and soils can act as sinks of species of inorganic mercury $\left(\mathrm{Hg}^{2+}\right)$, while they are simultaneously sources of volatile $\left(\mathrm{Hg}^{0}\right)$ and organic species, such as monomethylmercury (MMHg). Although the fraction of $\mathrm{MMHg}$ in total $\mathrm{Hg}$ of sediments is suggested to be as low as $0.1-1 \%$, MMHg is a serious threat for humans and wildlife due to its high potential for bioaccumulation and biomagnification and the ability to pass the blood-brain barrier. ${ }^{[1]}$ This is highlighted by exceptionally high $\mathrm{MMHg}$ concentrations found in fish and fish predators, as well as aquatic insects and birds living in close vicinity to $\mathrm{Hg}$ contaminated waterbodies. Humans are exposed to $\mathrm{MMHg}$ mainly by ingestion of (predatory) fish and rice.

One example of a highly $\mathrm{Hg}$ contaminated waterbody is Finow Canal, the oldest artificial waterway still in operation in Germany, with $\mathrm{Hg}$ mass fractions of up to or even more than 100 $\mu \mathrm{g} / \mathrm{g}$ found in the sediment, which are suggested to be attributable to a chemical plant producing (among other things) mercury-based seed dressings. Despite this high mass fraction of $\mathrm{Hg}$, anaerobic conditions, high amounts of organic matter and iron, which are all favorable for $\mathrm{Hg}$ methylation, ${ }^{[2]}$ no investigations of $\mathrm{Hg}$ speciation have been conducted there up to now.

We investigated $\mathrm{Hg}$ speciation in sediments of Finow Canal on length from before the known polluted sited into the confluence with another waterway using species-specific isotope dilution (SSID) GC-ICP-ToF-MS. Mass fraction of up to $41 \mathrm{ng} / \mathrm{g} \mathrm{MMHg}$ were determined in samples taken from Finow Canal and elevated concentrations could also be found around $14 \mathrm{~km}$ downstream of the confluence of Finow Canal with another waterway. In addition to this, highly toxic monoethylmercury (EtHg) could be detected in most of the sediment samples. These results are the first evidence of the occurrence of $\mathrm{MMHg}$ in this region and show the need for further investigation of the whole regional ecosystem, as well as the consideration of possible measures of remediation.

[1] F. Beckers and J. Rinklebe (2017), Crit. Rev. Env. Sci. Technol. 47, 693-794.

[2] C. T. Driscoll et al. (2013), Environ. Sci. Technol. 47, 49674983. 